\title{
CIENCIA DEL DERECHO Y FILOSOFÍA JURÍDICA EN EL UMBRAL DEL TERCER MILENIO: ¿MÁS ALLA DE UN PRE-ILUMINISMO?
}

\section{El foro y el saber generalizador de elevado contenido («alta abrangência»)}

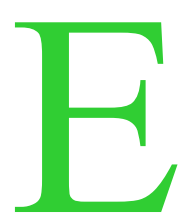

1 foro tiene su saber específico (de lo que es una técnica de aplicación judicial de normas), y este saber es dogmático, pues actúa en función de un dogma: la ley. En principio, la ley y las normas que la ley ordena aplicar, no se discuten, se aplican.

El choque entre esta postura dogmática, formalista (porque poco le importaría, en principio, el contenido de la ley, por ser ésta indiscutible) y los conocimientos generalizadores de elevado contenido (que contemplarían el derecho como algo no necesariamente coincidente con la forma legal, que sería una mera forma de expresión del poder) es anterior al tercer milenio y está bastante claro en nuestros días.

De ahí la frecuencia relativamente alta de decisiones praeter legem, adoptadas no en función de la letra de la ley, sino de fines sociales -que dicen ser los de la ley, pero que a menudo apenas se encuentran en ésta y nunca en el dispositivo formalmente pertinente. Por esta razón, existen las decisiones adoptadas «a contrapelo» («arrepio») de la ley, contra legem, no siempre confesadas con ese carácter contrario a la misma (es fácil siempre llamarlas armónicas con vagos principios generales de la legislación), pero de hecho opuestas al poder cristalizado en forma legal y tomadas en nombre implícito o explícito de una idea-sentimiento de justicia.

La posición dogmática-formalista es un residuo pre-iluminista ${ }^{1}$

${ }^{1}$ Por «iluminismo» aquí se entiende aquella postura surgida sobre todo a partir del siglo XVIII («siglo de las luces») que significó la reacción de la razón contra la mera autoridad, sea esta última laica o religiosa (cf. Binetti, 1986: 605-606 y 610-611). 
que tiene fuerza de poder judicial, no de rutina forense. Poco personal y muchos procesos refuerzan, incluida la carencia de tiempo para un examen más detenido de los procesos, esta rutina.

¿Es el poder judicial habitualmente legalista o el saber jurídico de elevado contenido -teórico-científico o filosófico- lo que ilumina la técnica del foro? Este dilema se profundizará a las puertas del tercer milenio. Si el iluminismo ya esclarece otros sectores estratégicos de la organización social, ¿por qué no habría de llegar al foro, en el tercer milenio, con fuerza «ideativa» preponderante? En definitiva, tenemos mil años por delante.

Esta transformación posible y hasta probable difícilmente se logrará sin el concurso de las instituciones de enseñanza de Derecho y de los juristas teóricos.

\section{La sujeción pre-iluminista del mundo académico al formalismo forense o social}

En el mundo jurídico académico del segundo milenio, se considera de forma general como realismo positivo una perspectiva exclusiva o casi exclusivamente hermenéutica en relación con el «derecho positivo»-esto es, en relación con las normas impuestas por el poder, fundamentalmente bajo la forma de ley estatal (cf. Wolf, 1961: 741 y 743). Las posiciones iusnaturalistas son consideradas románticas, anticuadas, vagas, inseguras, y consecuentemente casi totalmente excluidas del foro, donde predomina con elevada soberanía el dogma legal.

Así, en el mundo del foro y en el mundo académico que estudia y enseña sobre todo para la práctica forense actual, impera ampliamente la perspectiva de lege lata. La perspectiva lege ferenda concurre con la anterior, pero no prevalece sobre la primera, limitándose a una minoría de prácticos o teóricos del derecho de mente menos inmediatista.

No obstante, la situación pre-iluminista de los estudios jurídicos no se limita al legalismo dogmático sino que alcanza también a quienes niegan ese legalismo y defienden una concepción antitética en casi todo. Pues el punto común de convergencia de los dogmáticos estatalistas y de sus críticos sociales es que se sitúan mentalmente en un clima pre-iluminista de formalismo -en un caso formalismo estatal, en el otro social.

En la realidad, afirmar que es derecho lo que el Estado -identificable con el grupo de hombres del poder oficial- admita como derecho (cualquiera que sea su contenido) es tan vacíamente formal como afirmar que es derecho lo que el grupo social admita como 
derecho (cualquiera que sea el contenido). En uno y otro caso se trata de un formalismo, porque no importa para la determinación de lo jurídico cual sea su contenido, aceptado de forma estatal o social. Ese contenido puede, así, ser cualquiera. El formalismo social, por ser más amplio (cualquier grupo social, y no solamente el grupo social estatal, le determinaría), apenas elude su crudo formalismo, aunque crea la ilusión de alcanzar un contenido legítimo.

El formalismo social recorre prácticamente a todos los autores de la Sociología jurídica, incluso los más recientes. Un examen más atento descubriría, en realidad, que conocidas definiciones del derecho como hecho social, como las de Durkheim (1960: 27-34 y 205-209), Weber (1972: 17, 1960: 102), Ehrlich (1929: 399, Introducción 8, 29-30, 130 y 405), Gurvitch (1960: 189 y 188-190), Luhmann (1983: 105 y 104), y muchas otras, pueden poseer prácticamente cualquier contenido, pues pueden alcanzar contenidos claramente contradictorios, y, así, aparte de que el derecho sea un fenómeno social, afirman realmente muy poco.

Ni siquiera Cowan, a pesar de hablar de una compensación de valores de pensamiento con valores de sentimiento no jurídicos, llega a una especificación definitoria del derecho (Cowan, 1958: 471, 467 y 473).

Ahora bien, tanto el formalismo legal-dogmático como el socialcrítico son pre-iluministas porque ambos escapan a la cuestión de especificar conceptualmente una composición de contenido mental o social del derecho. Ambos son impotentes en apariencia para conocer una realidad que parece compleja y contradictoria, y se refugian en perspectivas cognitivas que son más que formales, formalistas, aunque más amplias que las anteriores por ser socio-grupales.

En realidad, afirmar que el derecho es un fenómeno estatal, o añadir que no es sólo estatal, sino social, e incluso anti-estatal, es muy poco, porque en definitiva todo eso quiere significar que el derecho es un fenómeno social, ya sea estatal o no. A esta evidencia es a lo que se limita casi siempre la determinación esencial que hacen de su objeto la ciencia y la filosofía jurídica actuales, con variaciones definitorias que no alcanzan realmente un contenido general real.

Imagínese una ciencia química que afirmarse tan sólo que el agua es un compuesto químico, y se despreocupase de su composición. Se podría entonces confundir $\mathrm{H}_{2} \mathrm{O}$ con $\mathrm{H}_{2} \mathrm{SO}_{4}$, ya que ambos son compuestos químicos. ¿Qué Química sería esa, incapaz de definir los contenidos de sus compuestos?

El derecho es un fenómeno social, pero otros fenómenos sociales no son derecho. Afirmar que el derecho es un fenómeno social (estatal o no) es perfectamente análogo, en su inespecificidad, a decir que el agua es un compuesto químico. 
Una ciencia jurídica o una filosofía del derecho con tal inespecificación, y, por tanto, con tal vaguedad, ¿pueden llegar sin pudor a un tercer milenio que probablemente será cada vez más iluminísticamente crítico?

Es preciso proclamar cuanto antes que el rey está desnudo para que éste pueda cubrirse. Cubrirse de una ciencia menos imprecisa y por tanto de una filosofía menos vaga ${ }^{2}$.

\section{Ciencia social y ciencia social del derecho en la transición hacia el tercer milenio: la denuncia científico-racional de los factores de desequilibrio}

Las ideologías y las filosofías de la justicia, de la libertad y de la igualdad pretenden explicar desde hace siglos los desequilibrios sociales, teniendo por finalidad la construcción, a través de la práctica, de sociedades armónicamente cohesionadas. Pero su discurso ha sido vago $\mathrm{y}$, de este modo, poco apto para contribuir a desarticular los centros reales del poder económico y político, que, por el contrario, extraen de ese carácter vago la posibilidad del uso de la bandera liberal al servicio de sus intereses. Así nos enfrentamos con concepciones que -en el propio nombre de la justicia y de un liberalismo de pretendidos resultados populares- legitiman aquel poder real de unos pocos.

Ahora bien, cualquiera que sea la ideología contemporánea que haya alcanzado el poder real, el equilibrio de las respectivas sociedades es claramente inestable, al vivir permanentemente todas las naciones en crisis más o menos acentuadas a nivel nacional o internacional. Un claro ejemplo de ello es la repentina y espectacular caída del llamado «socialismo real», que es realmente la caída de los socialismos dictatoriales europeos. $\mathrm{O}$ los súbitos levantamientos de grupos sociales discriminados y empobrecidos en un país que pretende ser el centro internacional de la democracia política. O los crónicos conflictos armados internacionales susceptibles de ser explicados por razones fundamentalmente económicas.

Por tanto, si el objetivo práctico es conseguir el equilibrio (cohesión,

${ }^{2}$ No se niega evidentemente que, bajo la influencia del iluminismo, se hayan realizado separaciones conceptuales, como aquella que distingue entre derecho y moral (en este sentido Coelho, 1987: 397). Pero esas separaciones, en razón de su carácter impreciso, son en rigor apenas pre-iluministas, ya que el iluminismo se caracteriza por el aprecio por la razón científica y, en consecuencia, por la mayor precisión posible, confiando en la extensión del resultado de las ciencias experimentales a todo el conocimiento (cf. Binetti, 1986: 606). 
integración) estable de las sociedades contemporáneas, existe evidentemente una falla para lograr tal objetivo. Entretanto, ¿tendrá una ciencia social, y una ciencia social del derecho, alguna respuesta para eso en estos últimos años de transición hacia el tercer milenio?

No se trata evidentemente de adaptar («engajar») la ciencia empírica, lo que tendría como resultado una ciencia bastante menos objetiva, al comprometerse previamente y con fuerza con una ideología; y por tanto con premisas, en la mejor de las hipótesis, dudosas (desde el punto de vista de la prueba empírica controlada del conocimiento). Se trata más bien de que, al describir y explicar la ciencia empírica la realidad tal como ésta parece ser, y al establecer sus proposiciones no simples correlaciones, sino más bien conexiones casuales, un resultado previsto científicamente se puede desear o no. Ahora bien, esa opción ideológica no tiene la posibilidad de perturbar la objetividad científica, simplemente porque es posterior a la actividad de la ciencia.

Jerarquía, competición (lucha pacífica) y conflicto (lucha) son procesos sociales de alejamiento en el espacio socio-interactivo que apenas pueden, en determinadas circunstancias, prevenir alejamientos aún mayores. Así, la lucha violenta de la policía contra los delincuentes puede prevenir la desintegración social más que si se dejase a éstos actuar sin control. Entretanto, no parece haber dudas razonables de que, en sí mismos, jerarquía, competición y conflicto son procesos siempre de alejamiento porque son explicables por la percepción (preponderante) de diferencias en el respectivo espacio socio-interactivo. De esa manera, en la medida en que disminuyan las posibilidades de alejamiento por la disminución de los procesos de alejamiento social, aumentarán las posibilidades de que éstos sean únicamente disociativos.

Por el contrario, la cooperación es siempre un proceso social de aproximación en el espacio social, sin restricción, pues es explicable por la idea de semejanza (preponderante) en su espacio socio-interactivo.

La ciencia describe y explica, no dice lo que debemos querer. Pero si queremos ideológicamente un equilibrio (cohesión, integración) social estable, la premisa para obtener ese efecto, lo sabemos científicamente, no puede poner el énfasis en la jerarquía, la competición y el conflicto, por la simple razón de que éstos son siempre procesos de alejamiento (desintegradores). Para lograr este efecto (equilibrio social estable), el énfasis tendrá que ponerse en el proceso de cooperación, que es siempre un proceso de aproximación (integrador).

Las dictaduras socialistas europeas se derrumbaron porque pusieron su acento en los procesos de jerarquización política y económica 
(estatalización enfática). Probablemente también se desmoronará el capitalismo, porque acentúa los procesos jerárquicos de poder económico y se afirma estar especialmente fundamentado en la competición, que es un proceso desintegrador. Y teóricamente, no considera que esos sistemas sociales hayan sido, en su inestabilidad, conflictivos y belicosos, aumentando con ello el espacio de desintegración.

Desde una perspectiva teórico-científica todo parece muy claro: la cooperación siempre aproxima, la jerarquización, la competición y el conflicto siempre alejan. Si se quiere que predomine la aproximación inter-humana, tendrá que ponerse el énfasis en la cooperación y no en jerarquías, competiciones y conflictos, aunque estos últimos procesos no parezcan eliminables de nuestra actual naturaleza humana que, evidentemente, no es angelical (para una exposición más detallada, Souto, 1984: 34-36, 38-39, 48-52, 57-59; 1988: 103-128; 1990: 535-563).

Todo parece indicar que a lo largo de la historia, se puede destacar la disminución, en general, del autoritarismo. Así, parece como mínimo posible, si no probable, que los próximos mil años se encaminen en el sentido de una atenuación no sólo de las jerarquías (que serían cada vez más grupales y menos personales), sino también de las competiciones y de los conflictos, con un aumento coetáneo de los procesos cooperativos. Correspondió a nuestra época la violencia nuclear contra Japón. Este hecho ha permanecido hasta ahora aislado, y no hay en la actualidad ni una impunidad de la violencia comparable a la de los déspotas antiguos, ni es la violencia de hoy tan manifiesta como la de los grandes de la antigüedad. Es muy posible entonces que tal tendencia no se invierta y que más bien progrese en el tercer milenio, lo que puede llevar a prestigiar más a la moralidad y la intelectualidad que al puro poder económico y/o político 3 .

Si una ciencia social menos imprecisa evidencia, con rigor metodológico, que la jerarquización, la competición y el conflicto son procesos sociales en sí mismos desintegradores, una ciencia social del derecho tendrá que intentar definir menos formalmente (y por tanto con menor imprecisión sustantiva o de contenido) su objeto. De este modo, le será posible establecer proposiciones menos formales y menos imprecisas en cuanto al contenido, sobre las relaciones entre derecho y realidad social.

${ }^{3}$ Reale observa analógicamente que el espíritu de la Era Contemporánea «es de creciente sentido axiológico», pues siente el hombre «todos los riesgos de perder el valor supremo de su ser personal en el Mundo». (Reale, 1981: 144) y Arnaud se refiere a la época posmoderna como un tiempo de esperanza (no de certeza, «pues el investigador es ante todo un escéptico)»: la esperanza de mejora de las condiciones sociales de vida. Época esa en que es preciso no sólo ver la influencia de la ética sobre el derecho, sino también la de los hechos (Arnaud, 1991: 248 e 229). 
Si se quiere calificar como «derecho» un fenómeno social que tenga el máximo posible de seguridad de contenido (y que no disponga sólo de la seguridad inestable de la fuerza), parece evidente que tendría que ser aquel fenómeno informado del conocimiento sustantivo menos inseguro de los que se conocen, el científico-empírico (conocimiento verificable a través de la observación controlada de los hechos). Derecho sería entonces la idea de «justicia» informada científico-empíricamente. Y una definición menos imprecisa en sí misma de «justicia», sería aquella que la contemplase, realistamente, tan sólo como el sentimiento de agradabilidad (sentimiento del «deber ser» del hombre normal -y detrás de este afecto, en cuanto fundamento del mismo, y fundamento de lo afectivo en general, estaría el poderoso impulso animal de conservación del individuo y de la especie, el impulso de «ser» (para una exposición menos sumaria, Souto, 1992: 19-48).

$\mathrm{Al}$ impulso de «ser» le importa fundamentalmente la conservación $\mathrm{y}$, en consecuencia, la cohesión, y la cohesión más estable posible, del grupo de que es parte, desde la sociedad humana hasta los grupos específicos. Esa cohesión, por tanto, interesa fundamentalmente al derecho, no entendido formalmente como poder estatal o social, sea cual sea su contenido, sino entendido en su contenido como idea, de acuerdo con la ciencia empírica e informando el sentimiento humano de agradabilidad.

Si hay, pues, ciertamente «legalidad» en el énfasis actual en los procesos sociales de jerarquización, competición y conflicto, difícilmente el tercer milenio llegará a ver la «juridicidad»-si es que desea la cohesión estable de los espacios sociales.

\section{Conclusión}

Si iluminismo significa espíritu libremente crítico y libremente creativo, todavía no hay iluminismo en un conocimiento jurídico que se considere sujeto a un dogma y que se vuelva imperialista más allá de sus límites propios y aceptables (que serían los de una ciencia, sobre todo, de la forma del derecho), no sin antes pretender, explícita o implícitamente, ser la ciencia jurídica -la ciencia del derecho «propiamente dicha», bajo el nombre manifiestamente no iluminista de Dogmática Jurídica.

Pero si esa ciencia formal del derecho es pre-iluminista y ese saber dogmático es insuficientemente crítico, también es pre-iluminista una ciencia social del derecho, ciertamente más crítica que la Dogmática Jurídica, aunque insuficientemente creativa -y precisamente por ello aún insuficientemente crítica. Pues esa ciencia social 
jurídica rehuye casi siempre el problema de la definición del contenido de su objeto, el derecho, amparándose en el formalismo de definirlo por las formas sociales con las que se presenta. En su lógica científica, utiliza métodos y técnicas de investigación cada vez más rigurosos, pero en cuanto a su objeto, no interviene en la lucha fundamental de la creatividad sustantiva. Existe como un temor a enfrentarse cara a cara con el objeto, aunque no con su contenido esencial. Y esa atmósfera definitoria pre-iluminista ensombrece la posibilidad de creación de proposiciones científico- sustantivas rigurosamente explicativas.

Por su parte, la Filosofía Jurídica, casi siempre sin una base disponible de ciencia empírica de derecho menos formalista y más sustantivamente rigurosa, no puede más que contar con demostraciones puramente racionales, sin control empírico riguroso, arriesgándose fuertemente a desvaríos de la razón que pueden expresarse en juegos de lenguaje y en «filodoxias» más o menos claras. Y se da aquí, de nuevo, un clima pre-iluminista (cf. Nader, 1991: 6 y 8).

A pesar de ello, ya existen indicios de concienciación respecto del problema y todo parece indicar que el tercer milenio se encaminará paulatinamente desde el formalismo teórico o práctico sobre el derecho hacia una crítica, en fin, iluminista, intelectualmente sustantiva y creativa, volcada en la definición y explicación científica y filosófica de contenidos sociales más definidamente realistas $\mathrm{y}$, por eso, que perciba mejor la realidad de los ideales.

(Trad. de Adelaide de Almeida Nascimento) 